\title{
Structural and thermal diffusivity studies of polycrystalline (CuSe)1-xSex metal chalcogenide compound
}

\begin{abstract}
This paper reports the preparation and the characterization of the $(\mathrm{CuSe}) 1 \overline{\mathrm{l}} \mathrm{xSex}$ metal chalcogenide semiconductor compounds with different stoichiometric compositions of Se (x $=0,0.2,0.4,0.5,0.6,0.8,1.0)$ in bulk form. The $(\mathrm{CuSe}) 1 \overline{\mathrm{I}} \mathrm{xSex}$ compounds were prepared using the solid state reaction by varying the ratio of $\mathrm{CuSe}$ :Se in the reaction mixture. X-ray powder diffraction analysis is used to identify and measure the mass absorption coefficient of the $(\mathrm{CuSe}) 1 \overline{\mathrm{I}} \mathrm{xSex}$ compounds to support the thermal diffusivity behaviour. The thermal diffusivity of the polycrystalline (CuSe) $1 \bar{i}$ xSex compounds were measured and analyzed for the first time, using the photoflash technique. The thermal diffusivity values were determined to be in the range of $2.524 \times 10 \overline{1} 3 \mathrm{~cm} 2 / \mathrm{s}$ to $1.125 \times 10 \overline{1} 2 \mathrm{~cm} 2 / \mathrm{s}$. It was found that the thermal diffusivity value tends to decrease as the parameter $\mathrm{x}$ increases. The relationship between the thermal diffusivity, mass absorption coefficient and density of the (CuSe)1ī xSex are discussed in detail.
\end{abstract}

Keyword: Thermal diffusivity; Metal chalcogenide compound 